BMJ Open

Sport \&

Exercise

Medicine

\section{'Take a Mental Break!' study: Role of mental aspects in running-related injuries using a randomised controlled trial}

To cite: de Jonge J, van Iperen L, Gevers J, et al. 'Take a Mental Break!' study: Role of mental aspects in running-related injuries using a randomised controlled trial. BMJ Open Sport \& Exercise Medicine 2018;4:e000427. doi:10.1136/ bmjsem-2018-000427

Accepted 9 August 2018
Check for updates

(C) Author(s) (or their employer(s)) 2018. Re-use permitted under CC BY-NC. No commercial re-use. See rights and permissions. Published by BMJ.

${ }^{1}$ Human Performance Management Group, Eindhoven University of Technology, Eindhoven, The Netherlands ${ }^{2}$ School of Psychology, Asia Pacific Centre for Work Health and Safety, University of South Australia, Adelaide, South Australia

${ }^{3}$ School of Sports Studies, Fontys University of Applied Sciences, Eindhoven, The Netherlands

${ }^{4}$ Department of Industrial Design, Eindhoven University of Technology, Eindhoven, The Netherlands

Correspondence to Professor Jan de Jonge; j.d. jonge@tue.nl

\section{ABSTRACT}

Background Running-related injuries (RRIs) can be considered the primary enemy of runners. Most literature on injury prediction and prevention overlooks the mental aspects of overtraining and under-recovery, despite their potential role in injury prediction and prevention. Consequently, knowledge on the role of mental aspects in RRls is lacking.

Objective To investigate mental aspects of overtraining and under-recovery by means of an online injury prevention programme.

Methods and analysis The 'Take a Mental Break!' study is a randomised controlled trial with a 12 month follow-up. After completing a web-based baseline survey, half and full marathon runners were randomly assigned to the intervention group or the control group. Participants of the intervention group obtained access to an online injury prevention programme, consisting of a runningrelated smartphone application. This app provided the participants of the intervention group with information on how to prevent overtraining and RRls with special attention to mental aspects. The primary outcome measure is any self-reported RRI over the past 12 months. Secondary outcome measures include vigour, fatigue, sleep and perceived running performance. Regression analysis will be conducted to investigate whether the injury prevention programme has led to a lower prevalence of RRls, better health and improved perceived running performance. Ethics and dissemination The Medical Ethics Committee of the University Medical Center Utrecht, the Netherlands, has exempted the current study from ethical approval (reference number: NL64342.041.17). Results of the study will be communicated through scientific articles in peer-reviewed journals, scientific reports and presentations on scientific conferences.

\section{INTRODUCTION}

Running, and long-distance running in particular, is becoming increasingly popular among participants of recreational sports activities. Globally, millions of people run on a regular basis, accompanied with an increasing number of running events such as half and full marathons. ${ }^{1}$ In the European Union, approximately 50 million people partake in running, ${ }^{2}$ while in the USA there are about 42 million running participants. ${ }^{3}$ With approximately 2.4 million practitioners, running is also one of the most popular sports in the Netherlands. ${ }^{2}$

Running is characterised by its nature of ease and simplicity, by being not very expensive to participate in, and by the opportunity it provides to practice whenever and wherever possible. ${ }^{45}$ Running provides many health benefits, such as lower risks of cardiovascular, metabolic, neurological, pulmonary, and even psychological and psychiatric diseases. ${ }^{6} 7$ Furthermore, sustained running over the longer term is related to reduced disability at higher ages as well as a significant survival advantage. ${ }^{69}$

However, a major drawback of running is that runners are very prone to running-related injuries $\left(\mathrm{RRIs}^{10}\right)$. The incidence and prevalence rates of RRIs reported in the literature range from 3.2-92.0\%, depending on the definition of RRI used and the population studied. Obviously, most RRIs involve the lower extremities, such as the knee, thigh and calf. ${ }^{112}$ In the Netherlands, the risk of injury in running is about three times higher than in other sports, and its prevalence is one of the highest among all sports. ${ }^{13}$ From a societal point of view, RRIs cost society a large amount of money due to medical costs and costs arising from work-related sickness absence and reduced work productivity. ${ }^{14} 15$ For that very reason, Jungmalm and associates $^{5}$ concluded that RRIs can be viewed as the primary enemy of runners, and the public health gains of keeping runners active should not be underestimated.

The consequences of RRIs for both runners and society emphasise the need for injury prevention programmes. Most researchers agree that the majority of RRIs are sustained as a consequence of structural overuse or overtraining ${ }^{16}$ or as a consequence of 
underrecovery. ${ }^{17}$ Yet, most existing literature on injury prediction and prevention focuses on the physical aspects of overtraining and underrecovery. ${ }^{12} 1819$ This is remarkable, as it largely neglects the mental aspects of overtraining and underrecovery, despite the potential role of mental aspects in injury prediction and prevention mentioned in the literature. ${ }^{162021}$ As a result, evidence-based knowledge on the role of mental aspects in RRIs is lacking. For that reason, the aim of the present study is to investigate this particular role by means of an online injury prevention programme.

\section{The role of mental aspects in running-related injuries}

In training sessions and races, runners are exposed not only to physical demands, but also to cognitive and emotional demands. Cognitive demands are efforts that impinge primarily on information processing and complex decision-making, and refer to focus, concentration, precision and tactics. ${ }^{22}$ For instance, long-distance runners often have to run precisely, focused and concentrated. During running races, they need to retrieve previously stored information about tactics and opponents. Emotional demands are mainly concerned with dealing with criticisms, disappointments, conflicts, an awkward audience, or a negative team atmosphere.$^{22}$ For example, a runner may have to deal with cancelling a race due to RRIs, or feel frustrated about a conflict with the coach, or may be very disappointed about his or her training progress.

To deal with the demands in their sport, runners can use different strategies and means. ${ }^{22}$ First, they can employ situational resources to which they have access. Situational resources are resources available in the running environment, such as control over tasks, access to advice and information, or empathy and help from a coach. It has been suggested that balancing high demands (eg, high levels of concentration, a negative team atmosphere) with sufficient, corresponding resources (eg, control, emotional support from teammates) is important to stay motivated, to feel healthy, and to perform optimally. ${ }^{22}$ However, when there are insufficient resources available to deal with running-related demands (ie, a high demands-low resources imbalance), negative consequences such as a lack of motivation, ${ }^{23}$ athlete burnout, ${ }^{24}$ decreased performance ${ }^{25}$ and even injury ${ }^{26}$ may ensue for running athletes.

A second strategy that runners can employ is to balance running-related demands with adequate recovery. Recovery takes place away from the running environment, and is generally defined as a return to and stabilisation at baseline level of psychophysiological systems which were activated during the running effort. ${ }^{27}$ Consequently, recovery is considered to be an integral part of running training and vital in preserving runners' health and performance. ${ }^{17} \mathrm{~A}$ large body of research has investigated the role of a variety of strategies aimed at promoting physical and physiological recovery from training and match demands. ${ }^{28}$ In contrast, studies investigating the role of mental recovery, which encompasses cognitive and emotional aspects, are scarce.$^{27}$ However, mental recovery strategies targeting changes in, for example, negative thoughts and mood are highly needed as they promote total recovery. ${ }^{29}$ Both a physical and a mental break from running-related activities, thoughts and emotions can help runners in achieving adequate and complete recovery from sport. Thus far, however, mental recovery has received little attention in the context of sports such as running. To conclude, in light of both physical and mental demands placed on runners, the buffering role of corresponding resources seems to be important to promote health and performance, as well as to prevent RRIs. Furthermore, the buffering role of both physical and mental recovery deserves attention in the prevention of RRIs and the promotion of runners' health and performance.

Another mental aspect which is underdeveloped in sports research is passion. Passion can be defined as a strong inclination toward an activity that people like, that they find important, and in which they invest time and energy. ${ }^{30}$ Vallerand's dualistic model of passion posits the existence of two types of passion-that is, obsessive and harmonious-that can be distinguished in terms of how the passionate activity is internalised into one's core self or identity. ${ }^{31}$ Obsessive passion can be described as a personal state in which the runner feels compelled to engage in running and loses control over running. Consequently, an intrapersonal conflict is experienced. The opposite is harmonious passion, which emphasises a personal state in which the runner feels engaged and has full control over running. From this perspective, the running activity is also in harmony with the person's other activities. Passion for running could be a relevant mental aspect in the understanding of perceived susceptibility to RRIs. More specifically, runners with obsessive passion may act compulsively towards their running-related demands and performance, may ignore a lack of resources, may disregard their need for recovery, may negate minor RRIs and overtrain themselves, leading to more serious RRIs in the long run. ${ }^{32}{ }^{33}$ Obsessive passion can therefore be seen as a mental risk factor for RRIs in runners. ${ }^{34}$ Taken together, we expect that obsessive passion will strengthen the effect of a high demandslow resources imbalance as well as the effect of a high demands-low recovery imbalance on RRIs, runners' health and performance.

Figure 1 represents the assumed relations between our predictor variables (ie, demands), situational moderators (ie, resources, recovery), personality moderator (ie, passion) and running-related outcomes (ie, RRIs, health, performance). In general, we hypothesise that an overload of running-related demands is positively related to RRIs, and negatively related to runners' health and performance. These relations are moderated by running-related resources, recovery and passion.

More specifically, we expect the following: 


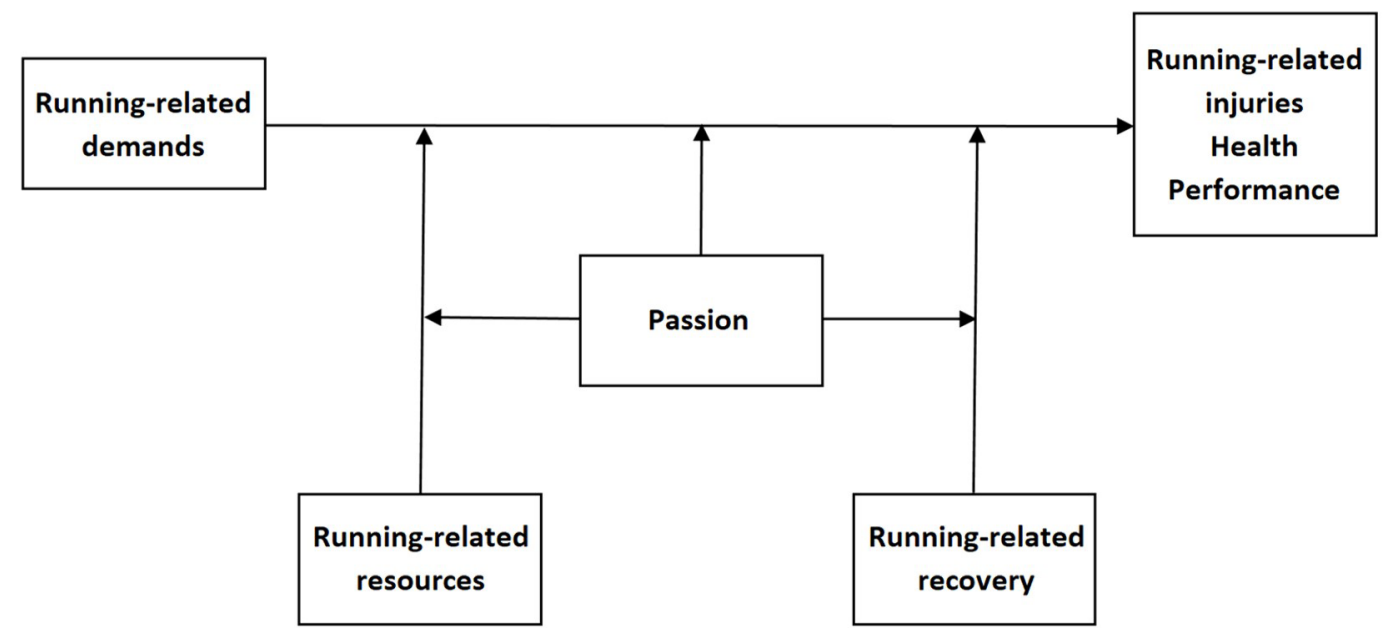

Figure 1 Research framework for the current study.

1. A high demand-low resource imbalance in long-distance running is associated with higher RRIs, adverse health and poor performance (ie, two-way interaction effects).

2. A high demand-low recovery imbalance in long-distance running is associated with higher RRIs, adverse health and poor performance (ie, two-way interaction effects).

3. Adverse effects expected in (1) and (2) are stronger if runners have an obsessive passion for running (ie, three-way interaction effects).

Testing of this research framework and its assumptions may enable the prevention of RRIs and optimisation of runners' health and performance.

\section{METHODS AND ANALYSIS}

\section{Study design}

The 'Take a Mental Break!' study consists of a randomised controlled trial ('wait list control group design') with a 12 month follow-up. Before the start of the trial, we conducted a baseline web-based survey study in February 2018 in which all the variables of figure 1 were included to test the psychometrics and parts of the predicted model. The trial took place in May and June 2018. During the 8 week trial, four bi-weekly surveys were administered. A selection of the intervention group was also asked to use activity trackers for the final 2 weeks of the trial. After the trial, two follow-up surveys identical to the baseline survey will be administered at 3 and 9 months after the intervention period. A flow chart of the study procedure is presented in figure 2 .

At the baseline measurement, every participant received a unique, secured link to the web-based survey, where they had to fill out their email address. These addresses function as ID tags for all follow-up measures. They are only available for the researchers and will only be used for analysis purposes. Monetary incentives will be offered to participants completing the web-based surveys as well as to participants completing the trial. All participants provided online informed consent.

\section{Study population}

Recruitment of recreational runners took place in January 2018 via three different sources: (1) top 20 largest athletics clubs in the Netherlands; (2) five Dutch Facebook running groups; (3) participants of the Eindhoven Marathon 2017. For the current study purpose, our target population comprised half and full marathon runners. Both novice and experienced runners could participate. The initial sample at the baseline examination consisted of 425 half and full marathon runners. More than half of the participants $(57.2 \%)$ were male and $42.8 \%$ was female. Mean age was 44.6 years $(\mathrm{SD}=11.7)$ with a range of $16-70$ years. Average running experience was 11.7 years $(\mathrm{SD}=10.5$; range 1-50). Approximately half of the participants performed organised running in groups $(48.0 \%)$, and $39.3 \%$ of the runners trained with a running coach. Six out of 10 runners $(60.7 \%)$ used a (personalised) training schedule for their training activities. Most of these figures are in line with those of the general Dutch running population. ${ }^{2}$ Of all the participants, $59.8 \%$ of the runners reported RRIs over the past 12 months. Injuries most frequently mentioned involved the knee $(26.8 \%)$, calf $(22.0 \%)$, Achilles heel $(18.5 \%)$ and foot $(18.1 \%)$. The mean duration of RRIs was 11.7 weeks $(\mathrm{SD}=16.3)$. These injury figures were comparable to other Dutch studies among long-distance runners. ${ }^{35}$

\section{Sample size calculation}

Sample size calculation was based on our primary outcome-RRIs. Using $\mathrm{G}^{*}$ Power $3{ }^{36}$ we conducted a power analysis based on a $10 \%$ reduction in injury prevalence over the past 12 months in our intervention group compared with the control group. Using pilot data, we calculated an effect size $\mathrm{D}$ of 0.24 , which is a small effect size according to Cohen. ${ }^{37}$ Using a statistical power of 0.80 , a type 1 error probability $(\alpha)$ of 0.05 , and an allocation ratio $(\mathrm{n} 2 / \mathrm{n} 1)$ of 1.00 , the total sample size required was $n=416(n=208$ for the intervention group and $n=208$ for the control group). 


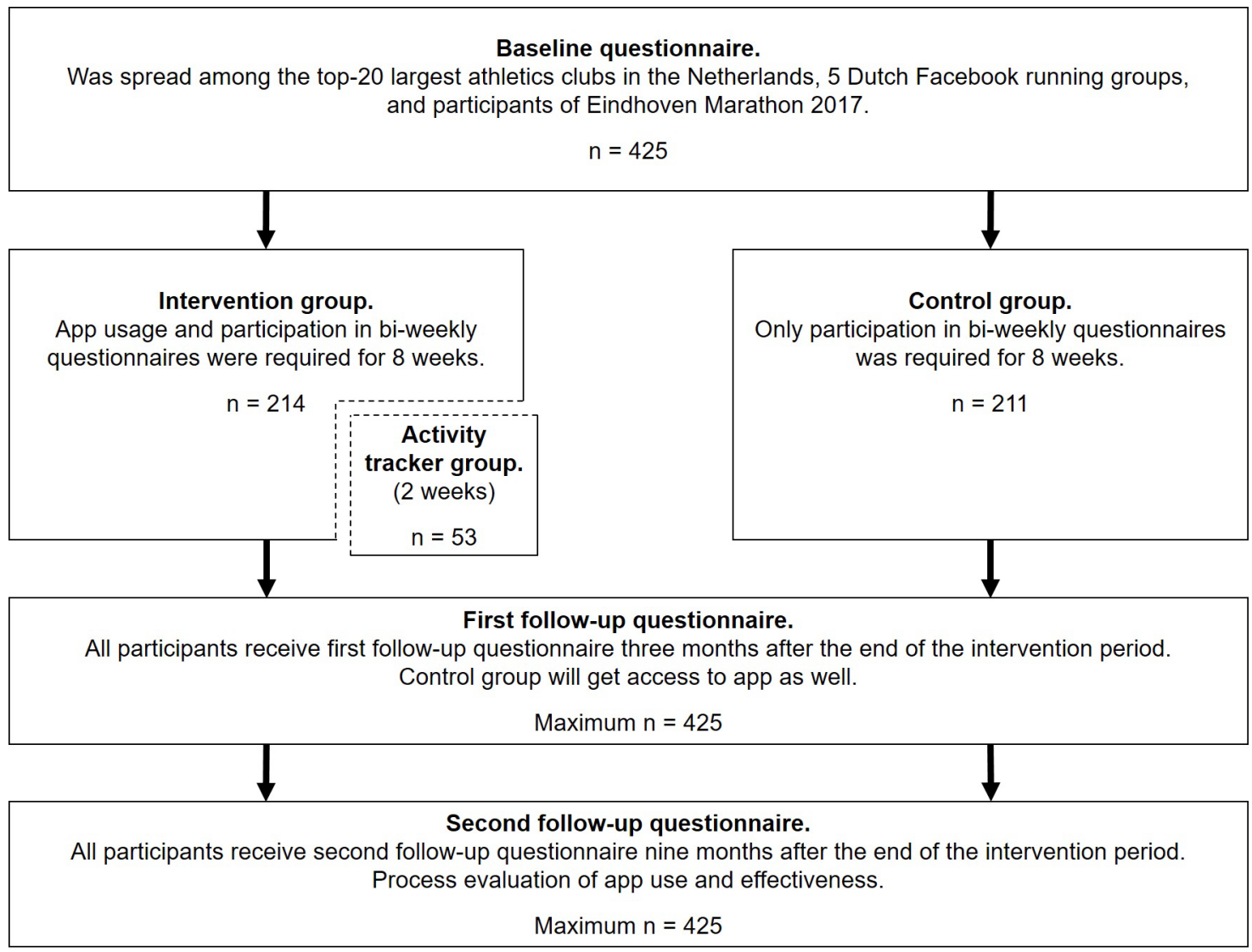

Figure 2 Flow chart of study design.

\section{Randomisation}

The 425 participants of the baseline survey were randomly assigned to the intervention group or the control group using computer-generated randomisation. As a result, the intervention group comprised 214 runners and the control group 211 runners.

\section{Injury prevention programme}

Participants of the intervention group received an email with an invitation to participate in the injury prevention programme developed by the researchers. This programme consisted of a running-related smartphone application (app) called REMBO (Running and Exercise Mental Break Optimisation) that could be downloaded and installed via a personal secured link (figure 3).

Electronic monitoring devices such as smartphone apps are becoming very popular nowadays, and are very suitable for intervention purposes. ${ }^{4}$ With the REMBO app, participants were asked to fill out 12 statements about their momentaneous mental and physical state. These 12 statements were based on scientific literature that dealt with mental aspects of RRIs, and were validated with empirical data from our earlier pilot studies. Examples are: "I am mentally very exhausted at the moment", "I feel obliged to go for a run right now", and "I did not sleep well last night". Items were scored on a scale ranging from 1 (not agree) to 7 (agree). Based on the results of these statements, the participants received advice on whether or not it was wise to go for a run at that moment. This advice was based on an evidence-based algorithm and was visualised by means of traffic lights: green, orange or red (see figure 3).

A green light implied a 'go' for running without any risks; an orange light implied that today's running was risky, and recommended following one of the items of advice from REMBO (eg, a shorter run, or taking a mental and/or physical break); and finally a red light implied a 'no-go' for running with strong advice to do something else such as taking a recovery day or going for an easy walk. All recommendations were based on recent literature and consultations with trainers and runners. Moreover, via the app, long-distance runners in the intervention group had access to offline and online information on how to prevent overtraining and RRIs with special attention to mental aspects (eg, mental recovery and obsessive passion). Long-distance runners in the control group had no access to the app and did not receive any preventive information. Finally, all participants in both groups were asked to fill out four bi-weekly surveys about their mental and physical state as well as the value and use of the app. After the first follow-up survey, runners in the control group will get access to the smartphone app and related preventive information. Finally, the REMBO app will be regularly upgraded based on our study results and feedback from users.

\section{Measures}

The measures that were used in both the baseline/ follow-up surveys and bi-weekly surveys are described 


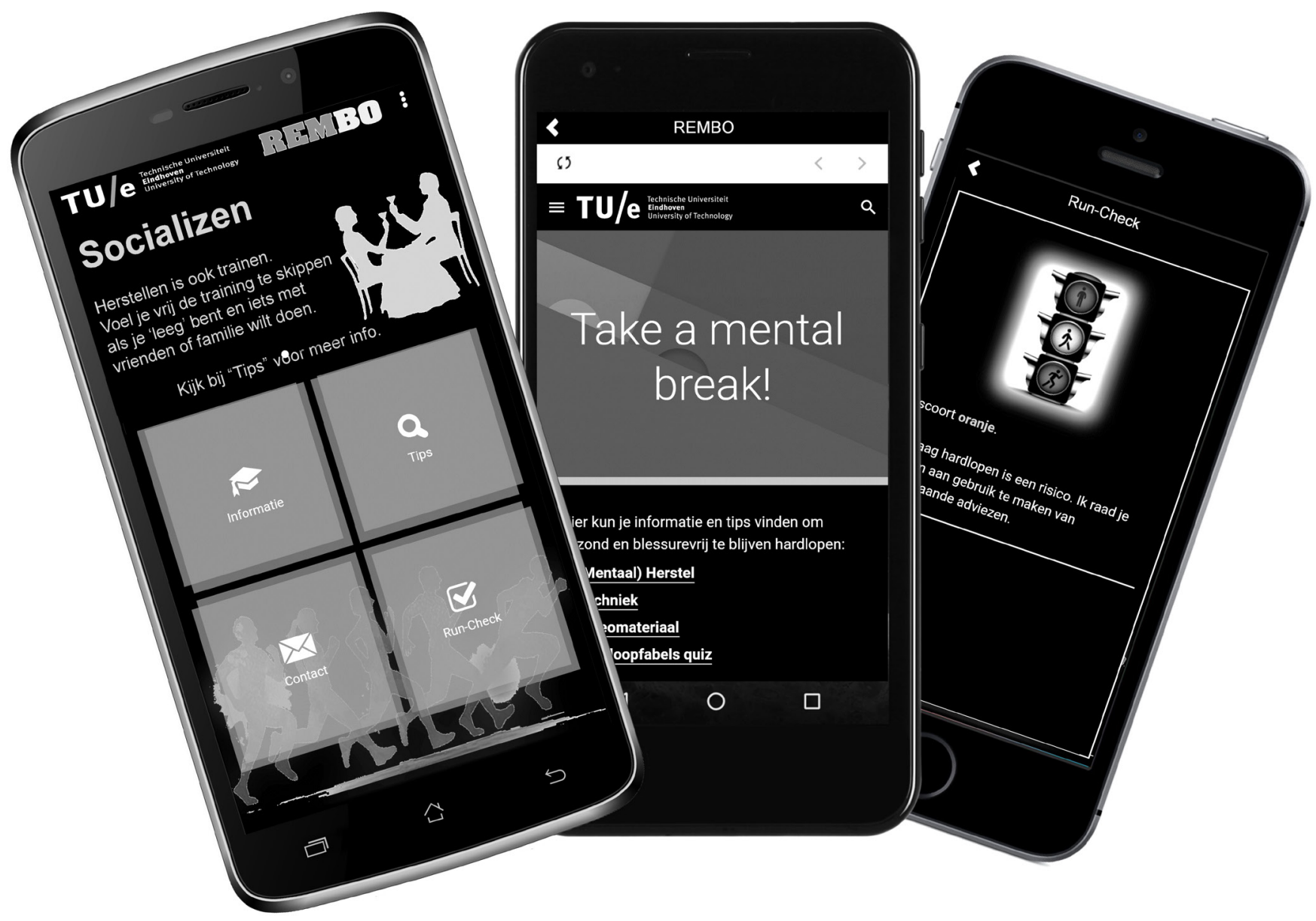

Figure 3 Running-related mobile application REMBO (Running and Exercise Mental Break Optimisation).

below. With minor adjustments, the items of the baseline web-based survey were made suitable for bi-weekly research (ie, momentaneous assessment). Participants will receive an email containing a secured link to the surveys. A reminder email will be sent after each survey to minimise dropouts.

The results of the interventions will be determined using the same measures. To control for differences between the intervention group and the control group as well as for possible confounders, several sociodemographic variables, anthropometrics and training characteristics were also recorded. Findings of the activity trackers will be used to check for self-report bias in several variables (eg, sleep) or convergent evidence between different kinds of assessments (eg, for running frequency, distance and sleep).

\section{Predictor and moderator measures}

Demands and resources in running sport were measured with the DISQ-SPORT. ${ }^{22}$ The sport-related demands scale consisted of 12 items measuring physical demands (four items; eg, "In my sport, I have to expend a lot of physical effort"), cognitive demands (four items; eg, "In my sport, I have to remember many things simultaneously"), and emotional demands (four items; eg, "In my sport, I have to deal with a negative atmosphere within the group I belong to"). The sport-related resources scale consisted of nine items measuring physical resources (three items; eg, "In my sport, I have the opportunity to take a physical break when things get physically strenuous"), cognitive resources (three items; eg, "In my sport, I have the opportunity to determine my own training method/s"), and emotional resources (three items; eg, "In my sport, I can find a listening ear in others (eg, teammates or coaches) when an upsetting situation has occurred"). For both demands and resources, runners indicated to what extent their sport requires them to deal with the three types of demands and to what extent they had access to the three types of resources. All items were scored on a 5-point Likert scale, ranging from 1 ((almost) never) to 5 ((almost) always).

Recovery from sport (ie, total detachment) was measured with a slightly adapted scale developed by de Jonge and colleagues, ${ }^{38}$ which also contained a cognitive, emotional and physical component. Each component was measured with five items, for example, "After running, I cognitively detach from my sport" (cognitive), "After running, I emotionally distance myself from sport" (emotional), and "After running, I physically detach 
from my sport (environment)" (physical). Items were scored on a 5-point Likert scale, ranging from 1 (never) to 5 (always).

Obsessive and harmonious passion were measured with 12 items adapted from scales developed by Vallerand and colleagues. ${ }^{30} 31$ Obsessive passion reflected a strong inclination where the runner feels compelled to engage in running, running takes a lot of space, the runner loses control over running, and conflict with other life activities is experienced. Harmonious passion emphasised a strong inclination where the runner feels engaged and has full control over running, and the activity is in harmony with the person's other activities. Each scale consisted of six items which were scored on a 7-point Likert scale, ranging from 1 (do not agree at all) to 7 (completely agree). Example items are: "The urge is so strong; I cannot help myself from doing running" (obsessive), and "Running is in harmony with other activities in my life" (harmonious).

\section{Outcome measures}

The primary outcome measure is any self-reported RRI over the past 12 months, which is defined as: 'an injury, impairment or wound, whether or not associated with pain, caused by or developed during a running training, that causes a restriction on running (in terms of duration, speed, frequency, distance, or intensity) or stoppage of running for at least 7 days or three consecutive scheduled training sessions'. This definition is slightly modified from the consensus statement of Yamato and his team. ${ }^{39}$ We assessed RRIs by means of a single question with a dichotomous response scale $(0=$ no; $1=y e s)$. In addition, participants were asked to indicate the location of the RRI (eg, knee, hamstrings, shinbone, or Achilles heel) as well as the duration of the RRI.

Secondary outcome measures can be categorised as health- and performance-related outcomes-that is, vigour, fatigue, sleep, and perceived running performance.

Vigour was assessed using the Shirom-Melamed Vigour Measure $^{40}$ that was adapted to the sport setting. The measure includes a 3-item subscale of physical strength (eg, "I feel I have physical strength"), 3-item subscale of cognitive liveliness (eg, 'I feel I can think rapidly"), and a 3-item subscale of emotional energy (eg, "I feel capable of being sympathetic to others (eg, teammates or coaches)"). Runners indicated to what extent they experienced each of the feelings described on a 5-point Likert scale, ranging from 1 (totally disagree) to 5 (totally agree).

General fatigue was measured using the Multidimensional Fatigue Symptom Inventory-Short Form (MFSI-SF) developed by Stein and associates. ${ }^{41}$ This measure consisted of 11 items reflecting physical, emotional and cognitive exhaustion. An example item is: "I feel emotionally exhausted". Items were scored on a 5-point Likert scale, ranging from 1 (never) to 5 (always), and summed up to obtain an overall assessment of general fatigue.
Sleep quality was measured by three items derived from the Maastricht Questionnaire. ${ }^{42}$ For instance, "Do you often have problems falling asleep?". The possible responses are 1 (no), 2 (sometimes), and 3 (yes). Added to this, we used one item to measure sleep quality (ie, "How do you rate the quality of your sleep?"), with a semantic scale ranging from 'very bad' to 'very good'. Finally, sleep duration was assessed using one item (ie, "How many hours do you sleep on average every night?"), with a scale ranging from $0-16$ hours.

Sleep quantity and quality were also measured with activity trackers (53 participants only). This enables us to compare survey and trackers' findings.

Perceived running performance was assessed using one item: "How do you judge your own running performance?" This item was scored on a scale ranging from 1 (very bad) to 10 (very good).

\section{Control measures}

Next to sociodemographic characteristics (ie, age, gender, education) and anthropometrics (ie, length, weight, body mass index, waist-to-hip ratio), several running-related characteristics (ie, running experience, running motives, number of matches in the past and forthcoming year, technical experience, use of mobile applications, foot landing type, shoe drop, strength training (yes/no), multisport, team/single running, trainer/coach (yes/ no), training schedule (yes/no)) were included to allow us to control for individual differences. Past studies have shown that each of these characteristics could have an influence on runners' injuries, and health- and performance-related outcomes. ${ }^{1135}$

\section{Intervention evaluation}

We will evaluate the short- and long-term effects of the running-related smartphone application REMBO with the first and second follow-up surveys, respectively. After the first follow-up survey, we will investigate whether the prevention programme has led to a lower prevalence of RRIs, better health and improved perceived running performance. After the second follow-up survey it can be determined if the expected positive effects of the programme were also noticeable 1 year after the baseline survey. Results from bi-weekly surveys will be used for analysing momentaneous effects. Finally, a process evaluation will be carried out to gain insight into factors that either stimulated or hindered successful use of REMBO, as well as the effectiveness of the app. We will therefore use a semi-structured questionnaire for all participants.

\section{Statistical analysis}

Hierarchical (linear/logistic) regression analysis will be applied to test cross-sectional relations between our predictors, moderators and outcomes. In order to analyse causal associations within the three different waves of all digital surveys, structural equation modelling will be used, as this technique is more useful to rule out alternative assumptions. Multilevel regression analysis will 
be used to investigate associations between predictors, moderators and outcomes based on data from the four bi-weekly surveys (level 1: four waves; level 2: week-level predictors and control variables; level 3: person-level predictors and control variables). To evaluate the results of the injury prevention programme after the follow-up measures, multilevel repeated measures analysis will be performed using MlwiN. ${ }^{43}$ This technique has several advantages compared with repeated measures multivariate analysis of variance (MANOVA), such as the inclusion of cases with incomplete data and less restrictive missing data assumptions. Finally, to study change in trials such as this one, knowledge about the type of change underlying the instruments used is needed. Next to assessing baseline factorial validity and reliability, the factorial stability over time (known as alpha-beta-gamma change) of the key measures will be examined. ${ }^{4}$ Dropouts will be documented and included in the data analysis to the point of dropout. Possible attrition effects (eg, spurious and under- or overestimated relations among the study variables) will be analysed according to the guidelines by Goodman and Blum. ${ }^{45}$

\section{DISCUSSION}

High injury rates among recreational runners and lack of empirical research into the role of mental aspects of injury prediction and prevention provide the impetus for the 'Take a Mental Break!' study. To our knowledge, this is the first study among long-distance runners that aims to investigate the role of mental aspects in running-related injuries using a randomised controlled trial. ${ }^{21}$ Reducing RRIs will facilitate runners to remain active, which in turn may contribute to their health, well-being and performance-not only in sports but also in work and private life. Almost needless to say, this can also reduce medical costs and costs due to absence from work or reduced work productivity.

The use and effectiveness of our running-related app REMBO will be tested among 425 half and full marathon runners. Via REMBO, runners in the intervention group had access to information on how to prevent overtraining and RRIs with special attention to mental aspects, such as how to take a mental break or how to deal with obsessive passion. Due to our wait list control group design, participants in the control group will get access to REMBO and related preventive information after the first follow-up measurement as well.

A strength of the current study is the unique combination of different research designs and methods. For instance, we used a randomised controlled trial, but we are also able to take advantage of a three-wave panel design and a daily diary design. Furthermore, we will conduct hierarchical linear and logistic regression analysis, multi-level regression analysis, and structural equation (causal) modelling. Finally, we collected both self-report and more objective data. This makes triangulation of different designs and methods possible.
A limitation of this study is that it could be biased by using self-report data of predictors, moderators and running-related outcomes. However, using more objective data retrieved from activity trackers makes a comparison between 'soft' and 'hard' measures possible. In addition, we tried to measure our self-report instruments as objectively as possible ('facts') with clear instructions to fill out, accompanied with concrete response rates as well as profound tests on validity and reliability. ${ }^{46}$

A final limitation is that self-reported RRIs are used. This implies that the runners had to judge the injury themselves, without a formal diagnosis from a medical practitioner. This is partly solved by providing the long-distance runners with a clear definition of RRI in all surveys.

In conclusion, the 'Take a Mental Break!' study offers a carefully considered triangulation of research designs and methods to assess the role of mental aspects in RRIs. At the same time, it tests the use and effectiveness of the newly developed REMBO app in how to prevent overtraining and RRIs, particularly from a mental perspective.

Contributors JdJ drafted this manuscript together with Lvl and JG, with feedback from SV. Lvl, JG and JdJ wrote the medical ethical approval application. The funding application was written by JdJ and SV. The trial was coordinated by Lvl. All authors approved the final manuscript.

Funding This study was funded by the Netherlands Organisation for Health Research and Development (ZonMW) (Grant Number: 536001003)

Competing interests None declared.

Patient consent Not required.

Ethics approval Medical Ethics Committee of the University Medical Center Utrecht, the Netherlands.

Provenance and peer review Not commissioned; internally peer reviewed.

Data sharing statement There are unpublished baseline data so far. All data are in Dutch, and may be shared upon request.

Open access This is an open access article distributed in accordance with the Creative Commons Attribution Non Commercial (CC BY-NC 4.0) license, which permits others to distribute, remix, adapt, build upon this work non-commercially, and license their derivative works on different terms, provided the original work is properly cited, appropriate credit is given, any changes made indicated, and the use is non-commercial. See: http:// creativecommons.org/licenses/by-nc/4.0/

\section{REFERENCES}

1. Hulteen RM, Smith JJ, Morgan PJ, et al. Global participation in sport and leisure-time physical activities: a systematic review and metaanalysis. Prev Med 2017;95:14-25.

2. Scheerder J, Breedveld K, Borgers J. Running across Europe: the rise and size of one of the largest sport markets. London: Palgrave Macmillan UK, 2015.

3. Running USA. State of the Sport - Part II: Running Industry Report. Running USA, 2014.

4. Janssen M, Scheerder J, Thibaut E, et al. Who uses running apps and sports watches? Determinants and consumer profiles of event runners' usage of running-related smartphone applications and sports watches. PLoS One 2017;12:e0181167.

5. Jungmalm J, Grau S, Desai P, et al. Study protocol of a 52-week Prospective Running INjury study in Gothenburg (SPRING). BMJ Open Sport Exerc Med 2018;4:e000394.

6. Lee DC, Pate RR, Lavie CJ, et al. Leisure-time running reduces all-cause and cardiovascular mortality risk. J Am Coll Cardiol 2014;64:472-81.

7. Lee DC, Brellenthin AG, Thompson PD, et al. Running as a key lifestyle medicine for longevity. Prog Cardiovasc Dis 2017;60:45-55. 
8. Chakravarty EF, Hubert HB, Lingala VB, et al. Long distance running and knee osteoarthritis. A prospective study. Am J Prev Med 2008;35:133-8.

9. Samitz G, Egger M, Zwahlen M. Domains of physical activity and all-cause mortality: systematic review and dose-response metaanalysis of cohort studies. Int J Epidemiol 2011;40:1382-400.

10. Videbæk S, Bueno AM, Nielsen RO. Incidence of running-related injuries per $1000 \mathrm{~h}$ of running in different types of runners: a systematic review and meta-analysis. Sports Med 2015;45:1-10.

11. van Gent RN, Siem D, van Middelkoop M, et al. Incidence and determinants of lower extremity running injuries in long distance runners: a systematic review. Br J Sports Med 2007;41:469-80.

12. Kluitenberg B, van Middelkoop M, Diercks R, et al. What are the differences in injury proportions between different populations of runners? A systematic review and meta-analysis. Sports Med 2015;45:1143-61.

13. Stam C. Hardloopblessures: Blessurecijfers 2014. Amsterdam: VeiligheidNL, 2016.

14. Hespanhol Junior LC, van Mechelen W, Postuma E, et al. Health and economic burden of running-related injuries in runners training for an event: a prospective cohort study. Scand J Med Sci Sports 2016;26:1091-9.

15. Valkenberg H, Sportblessures SC. SEH bezoeken. 2017. Amsterdam: VeiligheidNL, 2016.

16. Soligard T, Schwellnus M, Alonso JM, et al. How much is too much? (Part 1) International Olympic Committee consensus statement on load in sport and risk of injury. Br J Sports Med 2016;50:1030-41.

17. Kellmann M, Bertollo M, Bosquet L, et al. Recovery and performance in sport: consensus statement. Int J Sports Physiol Perform 2018;13:240-5.

18. McGlashan AJ, Finch CF. The extent to which behavioural and social sciences theories and models are used in sport injury prevention research. Sports Med 2010;40:841-58.

19. Bredeweg SW, Zijlstra S, Bessem B, et al. The effectiveness of a preconditioning programme on preventing running-related injuries in novice runners: a randomised controlled trial. Br J Sports Med 2012;46:865-70.

20. Fletcher D, Hanton S, Mellalieu SD. An organizational stress review: conceptual and theoretical issues in competitive sport. In: Hanton S, Mellalieu SD, eds. Nova Science. New York: Literature reviews in sport psychology, 2006:91-126.

21. Ivarsson A, Johnson U, Andersen MB, et al. Psychosocial factors and sport injuries: meta-analyses for prediction and prevention. Sports Med 2017;47:353-65.

22. Balk YA, De Jonge J, Oerlemans WGM, et al. Balancing demands and resources in sport: adaptation and validation of the demandinduced strain compensation questionnaire for use in sport. $J$ Sports Sci Med 2018:17:237-44.

23. Tabei Y, Fletcher D, Goodger K. The relationship between organizational stressors and athlete burnout in soccer players. J Clin Sport Psychol 2012;6:146-65.

24. Raedeke TD, Smith AL. Coping resources and athlete burnout: an examination of stress mediated and moderation hypotheses. J Sport Exerc Psychol 2004;26:525-41.

25. Halson SL, Jeukendrup AE. Does overtraining exist? An analysis of overreaching and overtraining research. Sports Med 2004;34:967-81.

26. Andersen MB, Williams JM. A model of stress and athletic injury: prediction and prevention. J Sport Exerc Psychol 1988;10:294-306.

27. Balk YA. Faster, higher, stronger: demands, resources, and recovery as determinants of elite athletes' well-being [dissertation]. Eindhoven University of Technology: Eindhoven, 2018.
28. In: Hausswirth C, Mujika I, Recovery for performance in sport. Human Kinetics: Stanningley, Leeds, 2013.

29. Rattray B, Argus C, Martin K, et al. Is it time to turn our attention toward central mechanisms for post-exertional recovery strategies and performance? Front Physiol 2015;6:1-14.

30. Vallerand RJ, Blanchard C, Mageau GA, et al. Les passions de I'ame: on obsessive and harmonious passion. J Pers Soc Psychol 2003;85:756-67.

31. Vallerand RJ. On passion for life activities: the dualistic model of passion. Advances in experimental social psychology. . Zanna MP, editor. New York, NY, Academic Press 2010:Volume 42. 97-193.

32. Rip B, Fortin S, Vallerand RJ. The relationship between passion and injury in dance students. J Dance Med Sci 2006;10:14-20.

33. Stephan Y, Deroche T, Brewer BW, et al. Predictors of perceived susceptibility to sport-related injury among competitive runners: the role of previous experience, neuroticism, and passion for running. Appl Psychol 2009;58:672-87.

34. Schwetz N. The influence of demands, resources and recovery on positive and negative outcomes for runners [master thesis]. Eindhoven: Eindhoven University of Technology, 2017.

35. van Poppel D, de Koning J, Verhagen AP, et al. Risk factors for lower extremity injuries among half marathon and marathon runners of the Lage Landen Marathon Eindhoven 2012: A prospective cohort study in the Netherlands. Scand J Med Sci Sports 2016;26:226-34.

36. Faul F, Erdfelder E, Lang AG, et al. G*Power 3: a flexible statistical power analysis program for the social, behavioral, and biomedical sciences. Behav Res Methods 2007;39:175-91.

37. Cohen J. Statistical power analysis for the behavioral sciences. New York: Routledge, 1988.

38. de Jonge J, Spoor E, Sonnentag S, et al. "Take a break?!" Off-job recovery, job demands, and job resources as predictors of health, active learning, and creativity. European Journal of Work and Organizational Psychology 2012;21:321-48.

39. Yamato TP, Saragiotto BT, Lopes AD. A consensus definition of running-related injury in recreational runners: a modified Delphi approach. J Orthop Sports Phys Ther 2015;45:375-80.

40. Shirom A. Feeling vigorous at work? The construct of vigor and the study of positive affect in organizations. In: Perrewe PL, Ganster DC, eds. Emotional and physiological processes and positive intervention strategies. . Oxford: Elsevier, 2004:3. 135-64.

41. Stein $\mathrm{KD}$, Jacobsen $\mathrm{PB}$, Blanchard $\mathrm{CM}$, et al. Further validation of the multidimensional fatigue symptom inventory-short form. J Pain Symptom Manage 2004;27:14-23.

42. Appels A, Höppener P, Mulder P. A questionnaire to assess premonitory symptoms of myocardial infarction. Int $\mathrm{J}$ Cardiol 1987; 17:15-24.

43. Rasbash J, Steele F, Browne WJ. A user's guide to MLwiN, Version 2.32. Centre for Multilevel Modelling: University of Bristol, 2015.

44. de Jonge J, van der Linden S, Schaufeli W, et al. Factorial invariance and stability of the Effort-Reward Imbalance Scales: a longitudinal analysis of two samples with different time lags. Int J Behav Med 2008;15:62-72.

45. Goodman JS, Blum TC. Assessing the non-random sampling effects of subject attrition in longitudinal research. $J$ Manage 1996;22:627-52.

46. de Jonge J, van Breukelen GJP, Landeweerd JA, et al. Comparing group and individual level assessments of job characteristics in testing the Job Demand-Control Model: a multilevel approach. Human Relations 1999;52:95-122. 